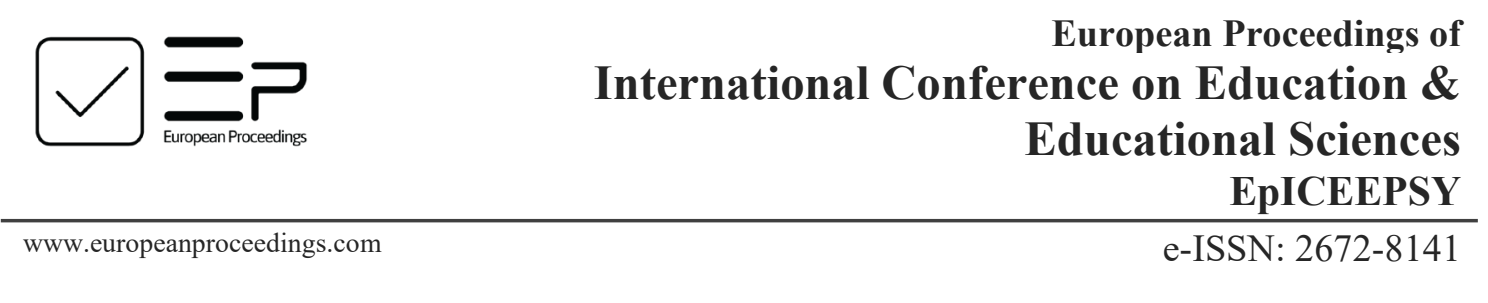

DOI: $10.15405 /$ epiceepsy.20111.29

$11^{\text {th }}$ ICEEPSY 2020

The International Conference on Education and Educational Psychology

\title{
A PILOT STUDY OF TEACHERS' FEEDBACK ACCORDING TO CAROL DWECK'S MINDSET THEORY
}

\author{
Marie Herynková (a)*, Kateřina Drašnarová (b), Karolína Očenášková (b), Alena Perglerová (b), \\ Silvie Urbanová (b) \\ *Corresponding author \\ (a) Faculty of Education, University of Hradec Králové, Rokitanského 62, Hradec Králové, Czech Republic. E-mail: \\ marie.herynkova@uhk.cz \\ (b) Faculty of Education, University of Hradec Králové, Hradec Králové, Czech Republic.
}

\begin{abstract}
Psychologist Carol Dweck distinguishes fixed and growth mindset based on people's belief that intelligence is fixed or malleable, respectively. Conducted studies show that fostering growth mindset can improve student's motivation and educational achievement. One of the main ways in which teachers can encourage the growth mindset is a way of giving feedback. The purpose of the current study is to assess the level of teachers' mindset according to the Mindset theory and detect whether teachers mindset is related to the way of giving feedback, particularly in response to flawless and fast student performance. Dweck Mindset Instrument (DMI) supplemented with additional questions was electronically administered to collect a set of data. The research group consisted of kindergarten, primary and secondary school teachers $(\mathrm{N}=175)$. The results show that teachers most often responded to a flawless and fast performance of a pupil with a generally positive assessment, positive assessment of abilities, reactions in the spirit of growth mindset, keeping pace with other students, describing or asking questions. No relationship was found between the mindset of teachers and the way they respond to the pupil's flawless and fast performance.
\end{abstract}

2672-8141 (C) 2020 Published by European Publisher.

Keywords: Feedback, growth vs. fixed mindset, teachers.

(i) $\$$ (C) The Author(s). This work is licensed under a Creative Commons Attribution-NonCommercial-NoDerivatives 4.0 International License (http://creativecommons.org/licenses/by-nc-nd/4.0/). 


\section{Introduction}

American psychologist Carol Dweck working at Stanford University brought scientific evidence showing that behind the success are not only our skills and talent but also our approach to them. How we perceive our abilities play a key role in our motivation and success (Blackwell et al., 2007; Dweck, 2015b; McCutchen et al., 2016). In her theory of mindset, she defines two types of approaches: growth and fixed mindset (Dweck, 1986). People who believe that intelligence and talent can be developed (growth mindset) are more successful than people who trust that intelligence and talent is something given and done (fixed mindset). According to the findings of Dweck and Molden (2018), the distribution of fixed and growth mindset is evenly represented in the population. Testing of children and adults shows that about $40 \%$ of people tend to endorse a fixed mindset, and about $40 \%$ tend to endorse a growth mindset, and about $20 \%$ are undecided. A significantly lower percentage of people with a fixed mindset (about 10\%) and a higher percentage of people with a growth mindset (around 75\%) were found in research among health students (Calo et al., 2019) or research among Turkish students - 18\% of people with a fixed mindset and $64 \%$ of people with a growth mindset (Altunel, 2019). A growth mindset can be fostered through in-school (Blackwell et al., 2007; Schmidt et al., 2017) or online (Paunesku et al., 2015) interventions in which children learn that intelligence can be developed over time through hard work, learning strategies, and help from others (Rattan et al., 2015). Currently, other psychological interventions are being developed aimed at changing the fixed mindset to growth and verifying their effectiveness (Yeager et al., 2016).

Dweck $(2008,2015 \mathrm{a}, 2015 \mathrm{~b})$ explored how parents and teachers influence their children's mindset through words and actions. They can lead them in the spirit of a fixed mindset that says: You have the qualities once given (such as a degree of talent) and I evaluate them. The second counterpoint is leadership in the spirit of a growth-oriented mind bearing the message: You are a person who is evolving, and I am interested in your development. Great teachers believe in developing intellect and talent and the learning process fascinates them. Teachers create an atmosphere of trust in class, not evaluation. They want to develop and teach their students, not assess the level of their intelligence and talent. He praises the effort, perseverance, the use of various strategies, progress, the desire not to give up and the ability to learn from failure. On the contrary, the praise of children's intelligence and talent harms their motivation and performance. Children can be convinced that if they succeed, they are smart, and if they fail, then they are silly. A fixed mindset leads to avoiding difficult tasks, resistance to failure, proving one's uniqueness, surrounding oneself with less successful ones, comparing oneself with others.

In a series of studies, Mueller and Dweck (1998) deliberately gave children three types of assessments to determine how the particular valuations would affect their performance. Some children were praised for their intelligence ("That's a high score; you must be smart at these problems"). Other children received praise that focused more on process rather than ability (,That's a high score; you must have worked hard at these problems “) or neutral praise („That's a high score “). Children praised for their intelligence tended to choose mainly the tasks they were able to handle, while children praised for their efforts chose tasks in which they could learn something new. The neutral praise about the work ("That's a high score") in the control group was similar to the performance-oriented praise (e.g. "good job") used by Butler (1987). Regarding positive achievement motivation, the best results were achieved by children praised for their 
efforts, followed by the control group praised for an outcome or a product nd the worst results were detected at a group of children praised for ability.

Dweck (2015b) further draws attention to the risk of praise for speed and perfection, as speed and flawlessness are the enemies of more demanding learning. Pupils may think, I'm smart when I'm fast and I don't make mistakes, I'd rather not do anything difficult" (p. 196). Dweck (2015b) recommends responding to a student's flawless and quick performance as follows: "I guess it was too easy. Sorry, I wasted your time. Let's embark on a task where you can learn something” (p. 196).

\section{Problem statement}

Teachers and parents greatly influence children's mindset. One of the main tools of influencing is providing feedback. Some teachers support the growth mindset of students with their feedback, others a fixed mindset. What influences the way teachers provide feedback? Are they influenced by their upbringing, pedagogical education and practice, the current mood, or by their mindset? It is largely unclear whether teachers' mindset influences the feedback they provide.

\section{Research Questions}

We operationalized these goals into the following research questions:

Question 1: How do teachers react to flawless and fast student's performance?

Question 2: Is there a relationship between teachers' mindset and the way they provide feedback to students?

\section{Purpose of the Study}

The study aims are to assess the level of teachers' mindset according to the Mindset theory and test whether teachers mindset is related to the way of giving feedback, particularly in response to flawless and fast student performance.

\section{Research methods}

\subsection{Instruments}

The recruited teachers completed an online survey consisting of the questionnaire of the American psychologist Carol Dweck (Dweck Mindset Instrument, DMI) supplemented with additional quantitative and qualitative questions. Dweck Mindset Instrument consists of 16 items that are rated on a 6-point Likert scale with $1=$ strongly agree to $6=$ strongly disagree.

The results presented in this paper relate to 5 quantitative questions (determining gender, age, length of practice, type of school, knowledge of Carol Dweck's book Mindset) and 1 qualitative question (asking for a response to a pupil's flawless and rapid performance). The qualitative question asking about the feedback that teachers give students was as follows: The student will complete the task you have given quickly and without any mistake (e.g. he/she will calculate a mathematical example). What would you usually say in such a situation? 


\subsection{Procedure and research sample}

The authors present an empirical study with mixed research design, the data were provided by a onetime questionnaire survey. The questionnaire was distributed through e-mail addresses and Facebook groups for teachers. The research group consisted of 175 people aged 20 to 60 years $(\mathrm{M}=41.86$; SD $=$ 11.23), who currently work as teachers with a length of practice of 1 to 40 years $(M=15.89 ; \mathrm{SD}=12.13)$. The sample included 59 teachers working in kindergarten (33.7\%), 66 teachers working in primary school (37.7\%), 21 teachers working in lower-secondary school (12.0\%), 15 teachers working at secondary schools $(8.6 \%)$ and 14 teachers working in several types of schools at the same time, e.g. primary and secondary schools $(8.0 \%)$. In terms of gender, there were 166 women $(94.9 \%)$ and 9 men $(5,1 \%)$. As for the knowledge of Carol Dweck's theory, only two respondents read her book Mindset, and one respondent read the articles and saw a video on ted.com. The remaining 172 respondents $(98.3 \%)$ probably do not know Carol Dweck's Mindset theory.

\section{Findings}

\subsection{Growth and fixed mindset of teachers}

The level of growth and fixed mindset was measured by a 16-item Dweck Mindset Instrument (DMI). The questionnaire was filled in by 175 people. The results show (see Table 1 ) that $20.6 \%$ of teachers have a fixed mindset (DMI score between 1.0 - 3.0), perceiving intelligence and talent as something given and unchanging, which they either have or do not have. Another $22.9 \%$ of teachers have a growth mindset (DMI score between $4.0-6.0$ ), perceiving intelligence and talent as something that can be significantly changed through effort and learning. The remaining 56.6\% of teachers were identified as undecided (DMI score between 3.1 - 3.9).

Table 01. The percentage of teachers with growth or fixed mindset, and those who were identified as undecided

\begin{tabular}{|l|l|l|l|}
\hline & & Number of Participants & \% \\
\hline \multirow{4}{*}{ Mindset Type } & Fixed Mindset & 36 & 20,6 \\
\cline { 2 - 4 } & Undecided & 99 & 56,6 \\
\cline { 2 - 4 } & Growth Mindset & 40 & 22,9 \\
\cline { 2 - 4 } & Total & 175 & 100,0 \\
\hline
\end{tabular}

\subsection{Analysis of teachers' feedback on flawless and fast student performance}

Teachers' feedback was processed qualitatively using the method of constant comparison. Subsequently, frequency analysis was used to indicate the frequency of respondents' answers to the individual categories created. The following seven categories emerged:

1. General positive evaluation (32.6\%) - most often the words "excellent" or "good work"

2. Positive assessment of abilities (18,9\%) - supports fixed mindset (eg. "You clever")

3. The reaction in the spirit of growth mindset (13.7\%) - appreciation of effort, preparation or progress, setting a more difficult example

4. Keep pace with other students (12.6\%) - wait for others, giving an example of the same difficulty; a call to check everything again; help another classmate 
5. Description (9.1\%) - a reaction "I see that you have everything done" or "you solved the task quickly and correctly"

6. Asking a question/questions (6.9\%) - respondents asked about the pupils' feelings or whether they enjoyed the task

7. Isolated reactions $(6.2 \%)$

\subsection{The relationship between growth and fixed mindset and teacher feedback}

We investigated whether the respondents, divided into individual categories according to the methods of giving feedback, differed from each other in the level of mindset (measured by the Dweck Mindset Instrument). Due to the fulfilment of the condition of homogeneity of variances for the variable mindset $(F=0.990 ; p=0.426)$, a parametric ANOVA test was chosen to determine the existence of differences between the groups divided according to the methods of feedback administration. There was no statistically significant difference in the level of mindset $(F=0.668 ; p=0.648)$ between the different groups of respondents divided according to the methods of giving feedback to students.

\section{Discussion}

In this subchapter, we will deal with the interpretation of the obtained results concerning the research questions and possible limits of the research. According to the findings of Dweck and Molden (2018), the distribution of fixed and growth settings of the mind is evenly represented in the population. Testing of children and adults shows that about $40 \%$ of people tend to endorse a fixed mindset, and about $40 \%$ tend to endorse a growth mindset, and about $20 \%$ are undecided. A significantly lower percentage of people with a fixed setting (about 10\%) and a higher percentage of people with a growth setting (around 75\%) were found in research among Australian health students (Calo et al., 2019). Similarly, the research among Turkish students presented $18 \%$ of people with a fixed setting mindset and $64 \%$ of people with a growth mindset (Altunel, 2019). In our research group of teachers, there were identified only $21 \%$ of teachers with a fixed setting, $23 \%$ of teachers with a growth setting, and $56 \%$ of teachers were detected as undecided. Our results, as well as the research results of Calo et al. (2019) or the results of the Altunel (2019) research, do not agree with the findings of Dweck and Molden (2018). There is a possibility that this is due to the specificity of our research files (health students, teachers) or the use of a measuring tool that is not standardized for individual nationalities.

We found the answer to the first research question asking about the reaction of teachers to the fast and flawless performance of the student in the form of six categories using the method of constant comparison. Teachers responded with a generally positive assessment, positive assessment of abilities, reactions in the spirit of growth thinking, keeping pace with other students, describing or asking questions. A large number of positive reactions to the fast and flawless performance of the student indicates that teachers are happy for this performance. The question is whether they are aware of the risk of praising the flawless and fast performance. As Dweck (2015b) points out, a student can begin to avoid difficult tasks and consequently his/her ability to face challenges and overall willingness to learn something new decreases. 
The second research question concerned the relationship between teachers' mindset and the way they provide feedback to students. There was no statistically significant difference in the level of mindset between the different groups of respondents divided according to the methods of giving feedback to students. This may mean that there is no relationship. Teachers evaluate using words like you are handy/smart because they try to encourage the student's motivation and appetite for learning. They do not realize that it can be harmful to students. Even if they have a high growth setting themselves, they pass the evaluation in a fixed spirit. Conversely, fixed mindset teachers can appreciate the effort. The way of providing feedback can be influenced by education, upbringing, practice, or something completely different from the teacher's mindset. Another possible explanation of our research outcome is that the relationship is present, however, it has not been proven due to the data collection method. The method of providing feedback on the flawless and fast performance of the pupil/student was determined only by a questionnaire survey, based on which a typology was created. The answers in the questionnaires were usually brief, and it was not always possible to fully understand the exact meaning and the relationship of particular aspects. At the same time, there can be a difference in what the respondent thinks he/she would say in a given situation and what he/she would say in practice during class. It is likely that by observing teachers in everyday practice in response to a flawless and rapid performance of a student, we would obtain more valid data. We, therefore, recommend verifying further research. Other limitations of our study include the lack of representativeness of the research set related to occasional data collection.

\section{Conclusion}

The results show that the most common teacher's feedback on a student's flawless and fast performance includes a generally positive assessment, a positive assessment of abilities and reactions reflecting the growth thinking. Among our respondents, the way of providing feedback corresponded mostly to performance-oriented praise (e.g. ,good job “) used by Butler (1987) or to the fixed mindset. Teachers' feedback according to the growth mindset was represented only to a small extent, which is in agreement with the limited knowledge of Carol Dweck's Mindset theory among the surveyed teachers. The mindset is influenced by what parents and teachers tell children. We assumed that the way teachers provide feedback is based on their settings. However, no relationship was found between the measured level of fixed and growth mindset of teachers and their way of giving feedback. Given the impact and importance of teacher's feedback, we need to better understand why teachers provide a particular type of feedback to students.

\section{Acknowledgements}

This paper was supported by the Specific Research of the Faculty of Education, the University of Hradec Kralove 2020, No: 2104, entitled: Feedback in Teaching Communication at the First Stage of Primary School.

\section{References}

Altunel, İ. (2019). Bridging the Gap: A Study on the Relationship between Mindset and Foreign Language Anxiety. International Online Journal of Education and Teaching, 6(3), 690-705. 
Blackwell, L. S., Trzesniewski, K. H., \& Dweck, C. S. (2007). Implicit theories of intelligence predict achievement across an adolescent transition: A longitudinal study and an intervention. Child Development, 78(1), 246-263.

Butler, R. (1987). Task-involving and ego-involving properties of evaluation: Effects of different feedback conditions on motivational perceptions, interest, and performance. Journal of educational psychology, 79(4), 474-482.

Calo, M., Peiris, C., Chipchase, L., Blackstock, F., \& Judd, B. (2019). Grit, resilience and mindset in health students. The Clinical Teacher, 16(4), 317-322.

Dweck, C. S. (1986). Motivational processes affecting learning. American psychologist, 41(10), 10401048 .

Dweck, C. S. (2008). Mindsets: How praise is harming youth and what can be done about it. School Library Media Activities Monthly, 24(5), 55-58.

Dweck, C. (2015a). Carol Dweck revisits the growth mindset. Education Week, 35(5), 20-24.

Dweck, C. (2015b). Nastavení mysli: Nová psychologie úspěchu aneb naučte se využit svi̊j potenciál [Mind setting: A new psychology of success or learn to use your potential]. Jan Melvil Publishing.

Dweck, C. S., \& Molden, D. (2018). Mindsets: their impact on competence motivation and acquisition. In A. Eliot, C. Dweck, \& S. Yeager (Eds.), Handbook of competence and motivation (pp. 135-154). The Guilford Press.

McCutchen, K. L., Jones, M. H., Carbonneau, K. J., \& Mueller, C. E. (2016). Mindset and standardized testing over time. Learning and Individual Differences, 45, 208-213.

Mueller, C. M., \& Dweck, C. S. (1998). Praise for intelligence can undermine children's motivation and performance. Journal of personality and social psychology, 75(1), 33-52.

Paunesku, D., Walton, G. M., Romero, C., Smith, E. N., Yeager, D. S., \& Dweck, C. S. (2015). Mind-set interventions are a scalable treatment for academic underachievement. Psychological science, 26(6), 784-793.

Rattan, A., Savani, K., Chugh, D., \& Dweck, C. S. (2015). Leveraging mindsets to promote academic achievement: Policy recommendations. Perspectives on Psychological Science, 10(6), 721-726.

Schmidt, J. A., Shumow, L., \& Kackar-Cam, H. Z. (2017). Does mindset intervention predict students' daily experience in classrooms? A comparison of seventh and ninth graders' trajectories. Journal of youth and adolescence, 46(3), 582-602.

Yeager, D. S., Romero, C., Paunesku, D., Hulleman, C. S., Schneider, B., Hinojosa, C., \& Trott, J. (2016). Using design thinking to improve psychological interventions: The case of the growth mindset during the transition to high school. Journal of educational psychology, 108(3), 374-391. 